\title{
Editorial: Expanding the influence of concrete research and application
}

\section{Peter Hewlett}

Professor, Division of Civil Engineering, University of Dundee,

Dundee, Scotland; Chairman of the Editorial Board of the

Magazine of Concrete Research

Concrete is an ubiquitous material with remarkable versatility and, as such, spans a wide range in composition, design and performance. Concrete is subject to continual development and change; this trend is reflected in research and the resulting published literature reporting such research work. The Editorial Board of the Magazine of Concrete Research often asks 'What is the best way of presenting current developments, concerns and applications? Indeed, should the Magazine of Concrete Research be identifying and encouraging such developments and changes?'

It is fair to say that this journal has always responded to change relating to issues concerning concrete and the relevant research in these areas. As a result, the range of papers and topics covered reflect innovation, current understanding and technical trends, as well as concerns. In this regard, the Magazine of Concrete Research has always been an eclectic mix and can act as a stimulus for responsible change in materials, practices and techniques.

Consideration is being given as to how best to emphasise the changes that need to be addressed. It is also necessary to look for useful and practical outcomes from the research that is published herein and make papers that have this emphasis more prominent. For instance, featured and/or keynote papers may be produced, as well as individuals invited to write about specific issues. This would place the Magazine of
Concrete Research in the position of being both proactive and responsive.

Submitted papers can vary in their relevance and impact. The Magazine of Concrete Research is selective in what is accepted for publication and endeavours to maintain a high standard in its content and presentation. For instance, modern concretes and their mix designs have resulted in challenges covering workability and its retention. In addition, advanced experimental techniques and high- and ultra-high-strength concretes are becoming more widely used, and these need to be presented. Papers concerning extreme events such as earthquakes, wind, flooding and excessive loading would be welcome. Also, the use of computational modelling and matters relating to natural phenomena as well as sustainability and the environment would benefit from exposure.

As well as reacting to change, the Magazine of Concrete Research wishes to stimulate and encourage beneficial change change based on focused research and knowledge.

As readers will know, themed issues have been presented from time to time, and that will continue. In addition the intention is to focus on current changes and trends, and keep the Magazine of Concrete Research at the leading edge of concrete's development. You may have some suggestion as to how this objective can be achieved, in which case please let us know. 